\title{
Learning by Doing and Doing via Learning-A Double-loop Teaching Practice of the Weak Structure Problem of Database Management
}

\author{
Hsiu-Ju Chen \\ Department of Information Management, I-Shou University, Main Campus: No.1, Sec. 1, Syuecheng Rd., Dashu \\ District, Kaohsiung City 84001, Taiwan \\ * E-mail of the corresponding author: hjchen@isu.edu.tw
}

\begin{abstract}
Database management is a subject of weak structure in problem solving. Database management teaches students the design theory and also the practice of database. The course is also the only one which teaches database design theory. It builds students' problem solving capability in database for future career development. However, few studies clarify students' learning in problem solving of weak structure. Furthermore, learning effect and learner satisfaction also need clarification when students learn subjects of weak structure. With the importance of solving database learning problems of weak structure, this study adopts the double loops of teaching practices of learning by doing and doing via learning. And to understand students' learning, this study adopts quasiexperiment in its research method. Finally, data of twenty-five respondents were gathered. The results of paired t-test showed that students presented significant difference between pre-test and post-test in problem-solving, learning effect, and database table operations. However, the difference of learner satisfaction was not significant. The results indicate the importance of double-loop teaching in weak structure problem of database management. The teaching allows students to understand different thinking logics and problem solutions that have high-level and complex mind process. The double-loop teaching builds the foundations of students' profession area and accumulates current learning for future theory and practice learning required. For model validation purpose, twenty-four-month data analysis is conducted on a mock-up basis.
\end{abstract}

Keywords: Learning by doing, doing via learning, project management, problem-solving, learning effect

DOI: $10.7176 / \mathrm{JEP} / 12-20-04$

Publication date:July $31^{\text {st }} 2021$

\section{Introduction}

Problem solving is a complex process of human cognition (Bryce and Whitebread, 2012; Bulu, and Pedersen, 2012; Erbas, and Okur, 2010; Jacobse and Harskamp, 2012; Kazemi et al., 2010; Scherer, and Tiemann, 2012). The process of solving problems need to use diverse knowledge or capabilities no matter the problems are professional or daily life problems (Gange and Medsker, 1996). In the process of problem solving, learners need to solve problems based on learned messages. Therefore, learners need to gather information or to learn new knowledge or skills to solve problems (PISA 2012; Mayer 1990).

Problems include structure problems and weak structure problems. Structure problems have clear problem definition and conditions. Therefore, the solving of problems is easier. Nevertheless, problems of weak structure usually have problem definition of high uncertainty. The conditions are also vague or incomplete. Furthermore, the problems generally have more than one solution. As a result, learners generally cannot solve problems directly.

The solving of problems of weak structure includes learners' understanding of problem meanings and conditions. The understanding connects to existed concepts in learners' mind. With the connection, feasible thoughts are confirmed and possible solutions are proposed. Learners then analyze the feasibility of different solutions. Finally, learners monitor the process of problem solving and make judgements whether the problems are solved. They can even analyze and improve problem solutions. This makes problem solutions more feasible (Jonassen, 1997).

PISA (2012) and Scherer and Tiemann (2012) also agree the viewpoint of Jonassen (1997). The process of solving problems of weak structure includes the exploration of systematic problems. The connection of the exploration to known knowledge in mind forms learners' understanding of problem traits. It shapes plans of solution and executes the solution. Learners then monitor and reflect the feasibility of problem solutions. As a result, in solving problems of weak structure, learners not only use existed knowledge and skills, but use metaknowledge and meta-capabilities in solving problems. The knowledge and skills include domain knowledge, structure knowledge about problems, and construct skills of analogy, deduction, and inference (Chi et al.,1981; Voss,1988; Jonassen,1997; Jonassen, Beissner, and Yacci,1993).

Students are future pillars of countries, and they are also foundations of country development. Education roots in the changes of students' attitude and behavior. However, students' learning of weak structure problems 
in such situations are less discussed. This study is therefore motivated to adopt Dewey's learning by doing and also doing via learning as double loops in the course teaching model. Via the guidance of problem solving, the course attempts to put its learning into life and career development of students.

Database management is a compulsory subject in the department of information management. It teaches students the design theory and also the practice of database. The course is also the only one which teaches database design theory. It builds students' problem solving capability in database for future career development. Therefore, it is a core course in the department of information management. However, it solves problems of weak structure. In the design of database, the design usually has problem definition of high uncertainty, and the conditions are also vague or incomplete. Furthermore, the problems generally have more than one solution. As a result, learners not only use existed knowledge and skills, but use meta-knowledge and meta-capabilities in solving problems (Chi et al.,1981; Voss,1988; Jonassen,1997; Jonassen, Beissner, and Yacci,1993). This study thus intends to enhance students' learning of database management via the loops of both learning by doing and doing via learning.

\section{Literature Background}

2.1 Learning by Doing

In the recent decades, experience learning has been implemented in university engineering education (Abdulwahed \& Nagy, 2011; Alcota \& Gonzalez, 2011; Alejos, Fernandez, Sanchez, \& Cuiñas, 2011). Via concrete learning experience, learning cycles form. Furthermore, through re-activating related knowledge and learning experience processes, students produce and keep the linkage to knowledge. This further enhances learning effects.

In addition to life experience, learning activities in courses is also an important source of concrete experience. Via learning experience, students are guided their learning direction. With the accumulation of different learning experience, students can form their own learning experience via withdrawing from the learning experience. This builds and keeps the linkage to knowledge. This also increases learning effectiveness.

Dale (1946) views concrete experience as a start point of learning. Via the accumulation and development of concrete experience, students can turn to abstract learning. The concrete experience includes direct and purposive learning, iconic experience via observation, and symbolic experience via concepts. Among the learning, direct and purposive learning is mainly from individual senses, including eyes, ears, tongue, skins and nose. With the direct visual experience, hearing experience, taste experience, touch experience and smell experience, learning foundations are built and accumulated. Iconic experience via observation is gained via minds. Minds feel individual senses inside heart; minds even give imagination and creation. Consequently, individuals form different iconic experience. Finally, symbolic experience via concepts process learning experience from thoughts or concepts. It activates past experience and symbols and gives meanings to symbols.

According to Dale (1946), concrete experience plays an important role in teaching. It builds students' learning foundation and accumulates students' learned experience to apply in current learning. And the current learning accumulation founds for future learning and repeats in future learning (Dewey, 1997). Kolb (1984) assumes that experience learning includes concrete experience, reflective observation, abstract conceptualization and active experiment. With the repeated learning cycle, learners' learning is formed (Kolb \& Wolfe, 1981; Smith \& Kolb, 1985). Among them, concrete experience emphasizes learners' learning from feeling. Via special learning experience, learners produce strong feelings to people, things, and surroundings. And when the concrete experience is interesting, it enhances learners' learning willingness and participation (Akcan, 2011; AndreuAndres, \& Garcia-Casas, 2011). After learners pass the concrete experience stage, learners have chances to go to the reflective observation stage and abstract conceptualization stage. In the reflective observation stage, people can observe the changes in people, things, and surroundings from different perspectives and thoughts. Learners then further gain logics and concepts of analysis in abstract conceptualization stage. And they can patiently finish actual operation in the active experiment stage.

With the importance of learner effect and actual operation in learning by doing, this study therefore measures learning effect and database table operations. The measures facilitate to understand the results of students' learning by doing. The hypotheses are therefore proposed.

\section{H1: The pretest and post-test of learning effect differs in students' database management learning. H2: The pretest and post-test of database table operations differs in students' database management learning.}

\subsection{Doing via Learning - Project-based Learning}

I Dewey proposes that the crisis of school education lies in the unreal life experience (Dewey, 1998, 1944). The learning in class detaches from learners' actual life experience. Therefore, he proposes learning by doing and emphasizes that students should not just learn from static abstract knowledge of books. Instead, the continuous recombination of learning experience forms learners' learning. Therefore, learning by doing allows learners to 
gain concepts and theory via doing process, and doing via learning allows learners to learn actual operations in the learning process. Consequently, learners' mind and experience produce correspondence. And their learning forms.

Dewey (1998) and Kolb (1984) both emphasize the importance of education in experience changes. Via experience, the linkage between education and behavior forms. The self-actualization and social participation can also be achieved (Alaoutinen, Heikkinen, \& Porras, 2012; Elias \& Merriam, 1995).

Project-based learning is generally a team-based activity which lasts for a period time to gain results. It focuses on developing or creating new things, such as new knowledge or new method. It can be student-centered, problem-based and/or inquiry-based. Project-based learning allows students to study a real problem based on scene or problems. This allows learners' different linkage to knowledge (Yasseri et al., 2018).

Project-based learning is a way of teaching which is learner-centered. It involves a dynamic classroom teaching. In the teaching, learners can actively explore problems and challenges in the real world to gain deeper knowledge (Edutopia, 2016). Students can answer or study a complex problem to understand a subject in a longer time (Buck Institute for Education, 2020). In the process, students can try to solve complex problems in the real world that are meaningful to them.

Markham (2011) proposes that project-based learning combines knowledge and doing. Students not only learn knowledge and elements in core courses but use their knowledge to solve real world problems and produce important results. Project-based learning puts emphasis on students, rather on courses. This is an important global change which encourage intangible assets, such as motives, passion, creation, compassion, and robustness. Such assets cannot be taught from textbooks, but from experience to activate.

Project-based learning guides students to solve real world problems in school and community. Students need to propose results coordinative or personally to present their knowledge. This provides chances and challenges for students to explore real word problems, and, therefore, enhances the possibility to keep skills and concepts in the long term (Beverley, 2009).

Project-based learning intends to develop students' capability of problem solving and innovation (Mergendoller and Mergendoller, 2009). It needs learners to use various kinds of skills to show their learning results in different dimensions, such as critical thinking, planning making and problem solving. They need to work based on teams and thus learn different interpersonal skills. With the importance of problem solving in project-based learning, this study measures students' problem solving to understand students' skills and knowledge that presents in problem-based learning. This study also measures students' learner satisfaction to understand their learning psychology variation. The hypotheses were therefore proposed.

H3: The pretest and post-test of problem solving differs in students' database management learning. H4: The pretest and post-test of learner satisfaction differs in students' database management learning.

\section{Research Method}

With the importance of experience in education and the difficulties that teachers face in teaching occasions, this study adopts the double loops of learning by doing and doing via learning in teaching. The teaching allows students to understand different thinking logics and problem solutions that are high-level and complex mind process. The double-loop teaching builds the foundations of students' profession area and accumulates current learning for future theory and practice learning. The concept is shown in Figure 1.

And to understand students' learning, this study adopts quasi-experiment in its research method (Lee \& Kerlinger, 1999). The study measures learning effect, database table operation, problem solving, and learner satisfaction. The definitions are provided below and the question items are provided in the appendix.

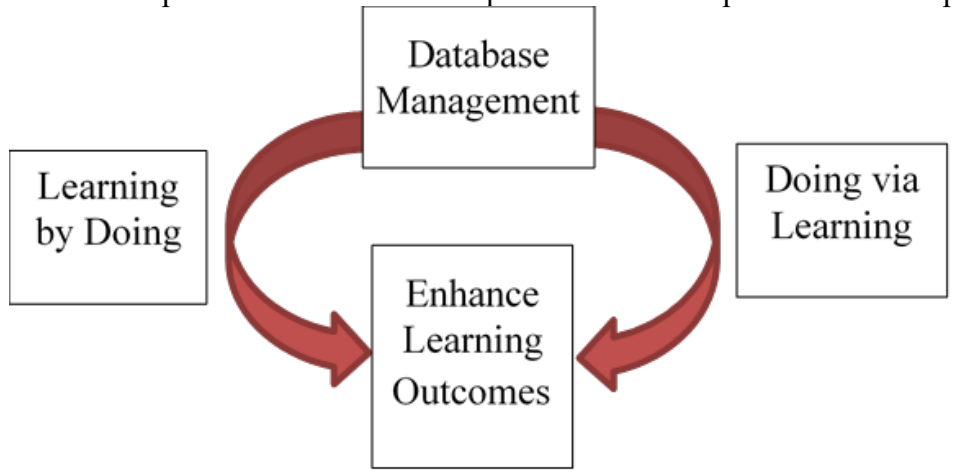

Figure 1. Double-loop Teaching

Problem solving. Problem solving is defined learners' ability to coordinate with others to solve real world problems (Dostál , 2015). The measure is based on the studiues of Dostál (2015), Bernhardt (1990), and 


\section{Zachman (1984).}

Learning effect. Learning effect is defined as learners' understanding of database design (Ramakrishnan and Gehrke, 2007; Welling and Thomson, 2017). The measure is based on Ramakrishnan and Gehrke (2007) and Welling and Thomson (2017).

Database table operations. Database table operations. is defined as learners' operations of database tables (Ramakrishnan and Gehrke, 2007; Welling and Thomson, 2017). The measure is based on Ramakrishnan and Gehrke (2007) and Welling and Thomson (2017).

Learner satisfaction. Finally, learner satisfaction is defined learners' satisfaction regarding the course of database management (Martin, 1988; Tough, 1982). The measure is based on the studies of Martin (1988) and Tough (1982).

In the first three weeks, students are only lecture-instructed. The first measure was done in the third week. In the following weeks of the semester, students needed to finish handouts after lectures. They needed to operate database tables. And they were also asked to propose a subject for projects to solve real problems in the world based on teams. In the process, students needed to finish the projects step by step and gave presentations in the middle term and in the final term based on teams. The second measure was then done after students finished their projects. Finally, data of twenty-five respondents were gathered. There were six females (24\%) and nineteen males $(76 \%)$ in the respondents. The means and standard deviations were shown in Table 1 . The method of paired t-test was then analyzed.

Table 1. Means and Standard Deviation of Measures

\begin{tabular}{|l|c|c|c|c|}
\hline \multirow{2}{*}{ Measure values } & \multicolumn{2}{|c|}{ Means } & \multicolumn{2}{c|}{ Standard Deviations } \\
\cline { 2 - 5 } & Pre-test & Post-test & Pre-test & Post-test \\
\hline Learning effect & 2.45 & 4.76 & 1.63 & 0.70 \\
\hline Database table operations & 1.03 & 4.80 & 0.17 & 0.68 \\
\hline Problem solving & 1.45 & 4.68 & 0.82 & 0.73 \\
\hline Learner satisfaction & 4.74 & 4.84 & 0.95 & 0.75 \\
\hline
\end{tabular}

\section{Research Results}

The results of paired t-test are shown in Table 2. They showed that students presented significant difference between pre-test and post-test in problem-solving, learning effect, and database table operations. However, the difference of learner satisfaction was not significant. Therefore, the hypotheses of $\mathrm{H} 1, \mathrm{H} 2$, and $\mathrm{H} 3$ were supported but not rejected. Nevertheless, H4 was rejected. The results indicated the importance of double-loop teaching in database management as weak structure problems.

Table 2. Paired t-test

\begin{tabular}{|l|l|l|}
\hline Paired t-test & $\mathrm{t}$ value & Significance \\
\hline Problem solving & -16.93 & $0.000^{* * *}$ \\
\hline Learning effect & -6.99 & $0.000^{* * *}$ \\
\hline Database table operations & -27.34 & $0.000^{* * *}$ \\
\hline Learner satisfaction & -0.46 & 0.648 \\
\hline
\end{tabular}

\section{Discussion}

About education, less literature discusses students' learning of problem solving in the situation of weak structure problems. To solve such problems, this study is therefore motivated to adopt the double loop learning of Dewey's learning by doing and also doing via learning in the course teaching model.

The analysis results show that regarding learning by doing, learners had significantly higher learning effect and database table operations than those under only lectures. The results imply that when experience learning is implemented in university information technology education, learning cycles of learners form via concrete learning experience. Learners reactivate related knowledge and learning experience process. Therefore, they produce and keep linkage to knowledge. Students' learning effects are then further enhanced. The results correspond to Abdulwahed and Nagy (2011), Alcota and Gonzalez (2011), and Alejos, Fernandez, Sanchez, and Cuiñas (2011). Learning activities in the course of database management has been an important source of concrete experience. And with the accumulation of different learning experience, students form their own learning experience via withdrawing from the learning experience in database of weak structure problem.

In addition, the results also show that regarding doing via learning, learners show significantly higher in problem solving. However, learner satisfaction did not show significant difference in the pretest and post-test. The results indicate that via project-based learning, students continuously recombine learning experience and form their learning. Therefore, learning by doing allows students to gain concepts and theory via doing process, and doing via learning allows them to learn actual operations in the learning process of database management of weak structure problem. Consequently, students' mind and experience produce correspondence. And the learning 
forms. This allows students' different linkage to knowledge (Yasseri et al., 2018). The results correspond to Dewey $(1998,1944)$ that students should not just learn from static abstract knowledge of books. Students should also learn by doing. However, the result of learner satisfaction is not significant. The results show that learner satisfaction lasts high when learners are guided in database learning.

To enhance students' preparation for future career development facilitates their enhancement of learning confidence. They know the way to solve database problems in the real world. This activates students to rethink about their learning from a different perspective. It becomes an important starting point for students to think about learning problems in the long run. In spite that learner satisfaction does not grow higher in the learning process, students know that they can go further via the class learning and they have the capability to solve problems in the real world (Smith \& Kolb, 1985).

\section{Suggestion and Future Study}

As a private university in Taiwan, our students are less confident than those in national universities. It is not uncommon that few of them perform well in class. MHowever, MMM,lokmkost of the students seem to believe themselves. But, they fall into the state of no confidence right away when they face problems in class. Some of them are not even willing to overcome learning problems. They just want to get answers directly. The learning process does not go further on these students. Such a situation not only affects students' learning but their career development in the future. To develop students' capability in class becomes a great challenge.

The study adopts both learning by doing and doing via learning in its teaching practice of information technology of database management. In the emphasis of both learning and doing, learners are allowed to use theory into practice. In such learning process, students are allowed to enhance their learning effect to prepare for future. They can practically design and use tables in database, and find the usefulness of the knowledge they have learned. They can also enhance their ability to solve questions regarding databases of weak structure in the real world.

However, the loading of teaching is higher in the double loops of learning by doing and doing via learning. Future studies that discuss teachers' teaching skills in information technology to lower teaching loading are suggested.

\section{Acknowledgement}

The author thanks the financial support of the Minister of Education in Taiwan under the grant number of PED1090641.

\section{Conflicts of Interest}

The author declares that there is no conflict of interest regarding the publication of this article.

\section{Reference}

Abdulwahed, M. \& Nagy, Z.K. (2011), “The TriLab, A Novel ICT Based Triple Access Mode Laboratory

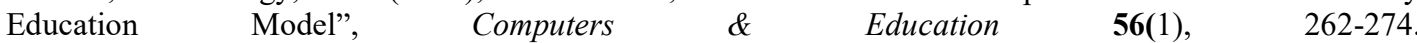
http://dx.doi.org/10.1016/j.compedu.2010.07.023

Alaoutinen, S., Heikkinen, K., \& Porras, J. (2012), "Experiences of learning styles in an intensive collaborative course", International Journal of Technology and Design Education 22(1), 25-49.

Alcota, M., Fuenzalida, A., Barrientos, C., Garrido, M., Ruiz de Gauna P. \& González, F.E. (2015), "An "XL" Endodontics Intervention for Dental Students Required to Repeat the Course: Changing Frustration to Improved Grades and Attitudes", Journal of Dental Education 79(4), 399-408.

Alejos, A.V., Gay-Fernández, J.A., Sánchez, M.G. \& Cuiñas, I. (2011), "Innovative Experimental Approach of Learning-through-play Theory in Electrical Engineering”, International Journal of Engineering Education 27(3), 535-549.

Andreu-Andrés, M. \& García-Casas, M. (2011), Perceptions of gaming as experiential learning by engineering students. International Journal of Engineering Education, vol. 27, pp. 795-804.

Bender, W.N. (2012), Project-Based Learning: Differentiating Instruction for the 21 st Century, Thousand Oaks, CA: Corwin Press. p.42. ISBN 978-1-4522-7927-5.

Bernhardt, B. (1990), “A Test of the Test of Problem Solving (TOPS)", Language, Speech, and Hearing Services in Schools 21(2), 98-101. https://doi.org/10.1044/0161-1461.2102.98

Bryce, D. \& Whitebread, D. (2012), The Development of Metacognitive Skills: Evidence from Observational Analysis of Young Children's Behavior During Problem-solving”, Metacognition and Learning 7(3), 197217.

Buck Institute for Education. (2020), What is PBL? Buck Institute for Education. https://www.pblworks.org/what-is-pbl. Retrieved 2020, 12-30

Bulu, S.T. \& Pedersen, S. (2012), "Supporting Problem-solving Performance in a Hypermedia Learning 
Environment: The Role of Students' Prior Knowledge and Metacognitive Skills", Computers in Human Behavior 28(4), 1162-1169.

Chi, M.T.H., Feltovich, P.J., \& Glaser, R. (1981), "Categorization and Representation of Physics Problems by Experts and Novices", Cognitive Science 5,121-152.

Crane, B. (2009), Using Web 2.0 Tools in the K-12 Classroom. New York: Neal-Schuman Publishers.

Dale, E (1946), Audiovisual Methods in Teaching. New York: Dryden Press.

Dewey, J. (1944), Democracy and Education. New York: The Free Press

Dewey, J. (1997), Experience and Education. New York: Free Press.

Dewey, J. (1998), Experience and Education: The 60th Anniversary Edition. West Lafayette, IN: Kappa Delta Pi. (Original work published 1938)

Dostál, J. (2015), “Theory of Problem Solving”, Procedia - Social and Behavioral Sciences 174(2), 2798 - 2805.

Edutopia, (2016), Project-Based Learning, Edutopia, March 14, 2016. https://www.edutopia.org/project-basedlearning. Retrieved 2020, 12-30

Erbas, A.K. \& Okur, S. (2010), "Researching Students' Strategies, Episodes, and Metacognitions in Mathematical Problem Solving", Quality \& Quantity 46(1), 89-102.

Jacobse, A.E. \& Harskamp, E. G. (2012), "Towards Efficient Measurement of Metacognition in Mathematical Problem Solving. Metacognition and Learning 7(2), 133-149.

Jonassen, D.H. (1997), "Instructional Design Models for Well-structured and Ill-structured Problem-solving Learning Outcomes", Educational Technology: Research and Development 45, 65-94.

Jonassen, D.H., Beissner, K., \& Yacci, M. (1993), "Structural Knowledge”, Hillsdale, NJ: Erlbaum.

Kazemi, F., Reza, M. \& Fadaee, S.B. (2010), "A Subtle View to Metacognitive Aspect of Mathematical Problems Solving”, Procedia - Social and Behavioral Sciences 8, 420-426.

Kolb, D.A. (1984). Experiential Learning: Experience as the Source of Learning and Development (vol. 1). Englewood Cliffs, NJ: Prentice-Hall.

Kolb, A.Y. \& Kolb, D.A. (2013), The Kolb Learning Style Inventory 4.0: A Comprehensive Guide to the Theory, Psychometrics, Research on Validity and Educational Applications. Boston: Hay Resources.

Kolb, D.A. \& Wolfe, D.M. (1981), Professional Education and Career Development: A Cross Sectional Study of Adaptive Competencies in Experimental Learning (ERIC Document Reproduction Service No. ED209493).

Larmer, J. \& Mergendoller, J. R. (2010), “Giving Students Meaningful Work”, Educational Leadership 68(1), 34-37,

Lee, H.B. \& Kerlinger, F. N. (1999), Foundations of Behavioral Research. New York: Holt, Rinehart, and Winston.

Markham, T. (2011), "Project Based Learning”, Teacher Librarian 39(2), 38-42.

Martin, C.L. (1988). "Enhancing Children's Satisfaction and Participation: Using a Predictive Regression Model of Bowling Performance Norms", The Physical Educator 45(4), 196-209.

Mayer, R.E. (1990), Problem Solving, in W. M. Eysenck (ed.), The Blackwell Dictionary of Cognitive Psychology, Basil Blackwell, Oxford, 284-288.

Ramakrishnan, R. \& Gehrke, J. (2007), Database Management Systems, 3rd McGraw-Hill, New York, NY

Scherer, R. \& Tiemann, R. (2012). Factors of Problem-solving Competency in a Virtual Chemistry Environment: The Role of Metacognitive Knowledge about Strategies. Computers \& Education 59(4), 1199-1214.

Smith, D. \& KoIb, D.A. (1986), User's Guide for the Learning Style Inventory. Boston: McBer edition.

Tough, A. (1982), Some Major Reasons for Learning. (Eric Document Reproduction Service No. ED 033251)

Voss, J.F. (1988), Problem Solving and Reasoning in Ill-structured Domains. In Antaki, C.(Ed.), Analyzing Everyday Explanation: A Casebook of Methods (pp. 74-93). London: Sage.

Welling, L. \& Thomson, L. (2017), PHP and MySQL Web Development. 5th Edition Addison-Wesley Professional

Yasseri, D, Finley, P.M., Mayfield, B.E., Davis, D.W., Thompson, P. \& Vogler, J. S. (2018), The Hard Work of Soft Skills: Augmenting the Project-based Learning Experience with Interdisciplinary Teamwork, Instructional Science 46(3), 457-488. doi:10.1007/s11251-017-9438-9. ISSN 1573-1952. S2CID 57862265

Zachman, L. (1984). TOPS: Test of Problem Solving. LinguiSystems, Moline, Ill.

try 37(3), 255-274. 
Appendix A. Measures.

\begin{tabular}{|c|c|}
\hline Construct & Measure \\
\hline \multirow[t]{6}{*}{ Learning effect } & I can understand the meaning and basic concepts of design of databases. \\
\hline & $\begin{array}{l}\text { I can understand the basic principles, development process and innovation keys of } \\
\text { databases. }\end{array}$ \\
\hline & I can choose, analyze and use basic knowledge of databases. \\
\hline & I can understand the basic knowledge to design databases. \\
\hline & I can understand the knowledge to choose adequate databases. \\
\hline & I can understand the current situation and development trends of databases. \\
\hline \multirow{7}{*}{$\begin{array}{l}\text { Database table } \\
\text { operations }\end{array}$} & I can design tables of databases. \\
\hline & I can build tables of databases. \\
\hline & I can use tables of databases. \\
\hline & I can increase tables of databases. \\
\hline & I can delete tables of databases. \\
\hline & I can update tables of databases. \\
\hline & I can query tables of databases. \\
\hline \multirow[t]{6}{*}{ Problem solving } & I can use the design flow to design actual database to solve real problems. \\
\hline & I can present innovative thinking in database implementation activities. \\
\hline & I have the capability to communicate, coordinate and cooperate with others. \\
\hline & $\begin{array}{l}\text { I can use design flow, plan, analyze, and excel project plans to solve real database } \\
\text { problems. }\end{array}$ \\
\hline & I can use knowledge and innovative thinking to design and implement databases. \\
\hline & I have the capabilities to coordinate and organize project teams. \\
\hline \multirow[t]{4}{*}{ Learner satisfaction. } & The questions include I feel satisfied with the practice of course materials. \\
\hline & I feel satisfied with the course of database management. \\
\hline & I feel satisfied with getting along with classmates. \\
\hline & Overall speaking, I feel satisfied with the course. \\
\hline
\end{tabular}

